\title{
Una metodología sociológica y narrativa para el análisis de relatos fotográficos
}

\author{
Mariona VisA BARBOSA \\ Universitat de Lleida \\ marionavisa@filcat.udl.cat
}

Recibido: $12 / 07 / 2012$

Aceptado: 20/09/2012

\begin{abstract}
Resumen
Este artículo expone la metodología utilizada para realizar un análisis de los álbumes fotográficos familiares desde una perspectiva sociológica y narrativa. Así, se explica la forma de estudio de un corpus que abarca 40 álbumes, existiendo muestras desde los años 60 del siglo XX hasta la actualidad. De ellos se realiza un análisis multidisciplinar que refleja que los álbumes son documentos que muestran la evolución que ha sufrido la sociedad en sus valores y roles. A su vez, el análisis narrativo muestra el cambio en la manera de contar la historia de nuestra vida como un relato a partir de las fotografías. La metodología utilizada es por tanto básicamente pragmática y además de las disciplinas descritas contiene una perspectiva tecnológica, semiótica y compositiva.
\end{abstract}

Palabras clave: fotografía, álbum familiar, sociología, narrativa

\section{A sociological and narrative methodology to analyse photographic stories}

\begin{abstract}
This paper exposes the methodology used to realize a sociological and semiotic-narrative analysis of the family albums. From a corpus that includes 40 albums sine the 60 s up to the current days, a multidisciplinary analysis is done, which reflects the evolution of our society in the change in familiar roles and the values. In turn, the narrative analysis shows the change in the way we explain the history of our life through the photographs. The used methodology is therefore basically pragmatic and besides the described disciplines it contains a technological, semiotic and compositive perspective.
\end{abstract}

Keywords: photography, familiar album, sociology, storytelling

\section{Referencia normalizada}

VISA BARBOSA, Mariona (2012): “Una metodologia sociológica y narrativa para el análisis de relatos fotográficos”. Estudios sobre el mensaje periodístico. Vol. 18, núm. especial noviembre, págs.: 929-939. Madrid, Servicio de Publicaciones de la Universidad Complutense.

Sumario: 1. Marco teórico y objeto de estudio. 2. Metodología. 3. Discusión. 4. Conclusiones. 5. Referencias bibliográficas

\section{Marco teórico y objeto de estudio}

Este artículo expone la metodología utilizada para realizar un análisis de los álbumes fotográficos familiares desde una perspectiva sociológica y narrativa.

Los antecedentes en estudios que tengan el álbum familiar como corpus de análisis tienen su referente en el estudio que el profesor Armando Silva (1998) realizó en el año 1998 sobre los álbumes familiares colombianos.

Silva realizó un análisis multidisciplinar de los álbumes de fotografía analógicos de las familias colombianas, desde una perspectiva visual, cultural y comunicativa. Sus estudios culminaron en el libro Álbum de familia: la imagen de nosotros mismos. Hasta entonces este estudio de los álbumes desde esta perspectiva era inédito, y ya en la introducción el autor deja claro que entiende su trabajo cómo una aportación con- 
ceptual y metodológica, que sirva para abordar el álbum de familia de cualquier comunidad internacional dónde este sea un hecho significativo en su vida social.

Para realizar el estudio, Silva analizó 100 álbumes de familias colombianas distribuidas en tres regiones: Bogotá. Medellín y Santa Marta. Estas regiones se dividieron también en clases sociales; alta, media y popular. Y se estudiaron tres periodos históricos: el llamado antiguo (antes de 1948), el intermedio (entre 1948 y finales de los setenta) y el nuevo, des de los años ochenta hasta finales de los noventa.

De los 100 álbumes analizados, se cogía la foto central de cada álbum (aquella más significativa para la memoria familiar) y también la primera y última del álbum. Así se creaba un mini-relato, siendo las tres fotografías sometidas a estudio tanto a nivel de construcción fotográfica como en condición de relato. En su estudio sólo analiza los álbumes que son familiares, los de una sola persona quedan fuera de la muestra.

El análisis que aquí exponemos bebe de las fuentes de Silva, pero amplia el estudio al análisis semiótico y narrativo. Para ello, como se explicará más adelante, se diseñó una parrilla original de recopilación de datos.

Las aportaciones de los norteamericanos Richard Chalfen (1987) y Nancy van House (2005) también son un gran referente a la hora de establecer los usos básicos de las fotografías.

Desde una perspectiva antropológica, Chalfen, en su libro Snapshots versions of life, de 1987, estudió lo que él llama "Kodak culture", examinando 200 colecciones de fotografías personales. Identificó tres funciones de la fotografía: documentación, soporte de la memoria y ayuda a formar parte de una cultura.

Nancy van House, de la Universidad de California, ha estudiado los usos sociales de las cámaras fotográficas, así como de los dispositivos telefónicos móviles con cámara y las plataformas más populares de intercambio de fotografías entre usuarios. En sus investigaciones se analiza con detalle el porqué del hecho de disparar y compartir fotografías más que aquello qué éstas muestran. En su estudio The Social Uses of Personal Photography, realizado en 2005, describe cuatro usos básicos de las imágenes personales:

1. el memorístico, narrativo e identitario: las fotografías nos ayudan a construir narraciones de nuestras vidas y a formarnos una idea de identidad y colectividad.

2. el de fundamentar relaciones sociales: las fotografías refuerzan los lazos entre generaciones y colectivos.

3. el de la auto representación: la fotografía nos permite mostrarnos tal y como queremos ser vistos por los demás. Los autorretratos, las imágenes de la familia y de los amigos, de las posesiones y de las actividades que desarrollamos, manifiestan nuestra manera de ser.

4. el de la auto expresión: las fotografías reflejan el punto de vista del autor, y muestran su concepción estética y creativa.

Nuestro estudio se centra sobre todo en el primer punto, ya que nos interesa estudiar de qué manera se generan narrativas a partir de las imágenes y como han cambiado a lo largo de las décadas. Los otros tres usos apuntados por van House son tratados en el análisis compositivo y de representación social. 
John Berger, en su libro Otra manera de contar (1997), establece un tipo de narración propia de las imágenes, dónde expone cómo cada imagen explica una historia que va más allá del momento congelado que representa, que tiene un pasado y un futuro. Este punto de vista será clave para la comprensión del relato de los álbumes de fotografía, ya que las imágenes que los conforman despliegan una historia a su alrededor que llena los espacios entre las fotografias.

Las aportaciones de Pierre Bordieu también son de gran relevancia en nuestro estudio, en concreto las de su libro La fotografía, Un arte intermedio, dónde reflexiona sobre cómo y por qué la fotografía es objeto de investigación sociológica. La fotografía, nos dice Bourdieu, deja entrever los "sistemas de esquemas de percepción", o el "sistema de valores implícitos del grupo" (Bourdieu, 1979: 67). Es decir que se trata de una manifestación que nos puede conducir hacia los esquemas de percepción más profundos. Ya en los años 60, Pierre Bordieu se preguntaba si la práctica de la fotografía y la significación de la imagen fotográfica podían proporcionar material para la sociología.

Erving Goffmann (2006), considerado como el padre de la microsociología, estudió las unidades mínimas de interacción entre las personas, centrándose en grupos reducidos como la familia. En 1959 publicó La presentación de la persona en la vida cotidiana, libro que analiza las interacciones sociales, considerando las persones como actores, bajo un enfoque dramatúrgico. Sus definiciones del rol como un conjunto organizado de expectativas de comportamiento entorno a una función o posición social han sido tomadas en consideración para el análisis de los roles narrativos que los familiares desarrollan en los álbumes. La idea de que cada persona asume uno o diversos roles en cada interacción, en función de la imagen que desea ofrecer a los otros, queda ejemplificada en los álbumes fotográficos, dónde se ofrece una versión determinada sobre nosotros mismos y la familia.

El trabajo analiza el objeto de estudio des de los años sesenta hasta la actualidad, por lo que nos encontramos con tres contextos sociales considerablemente diferentes. Las conclusiones sociológicas y narrativas que se extraen de los álbumes se contextualizan en tres períodos históricos a partir de las definiciones que el sociólogo Gilles Lipovetsky (2006) ha establecido en sus libros sobre modernidad, posmodernidad y hipermodernidad. Los valores propios de cada periodo han sido ampliamente definidos por este filosofo, y son completadas con las de Zigmunt Bauman (2004). Aunque partimos de sus teorías, en el trabajo el término posmodernidad ha sido sustituido por el de tardomodernidad, ya que creemos que los conceptos que representa empezaron a estar presentes en nuestra sociedad a partir de finales del siglo XIX. Es una época asociada a la representación y a la simulación, dónde los objetos producidos por las empresas (productos, servicios, marcas e instituciones en sí mismas) se convierten en imaginarios. (García, 2011:7). Veremos cómo las imágenes fotográficas son una herramienta clave para esta simulación de la versión de familia que se quiere transmitir.

El filosofo y antropólogo francés Paul Ricoeur (1987), des del análisis hermenéutico que propone en su libro Tiempo y narración, establece una propuesta para el análisis de los relatos. Sus teorías sobre las características narrativas de los relatos hechos a partir de la realidad, y sobre la trama como operación configurante que dota de inteligibilidad 
a los acontecimientos, han sido claves para entender el álbum familiar como una sucesión de tramas, a través de las cuales adquiere la categoría de historia o narración.

Y, obviamente, para efectuar el análisis semiótico-narrativo se ha seguido los postulados del semiótico Julius Greimas (1979). A partir de su modelo actancial y su definición de la estructura canónica, se puede encontrar la estructura típica de la mayor parte de relatos, y hemos aplicado su esquema para encontrar el programa narrativo de los álbumes de fotografía.

Así pues, el trabajo realiza un análisis multidisciplinar de los álbumes de fotografía, a partir de la aplicación de las teorías y estudios de los autores más destacados en las disciplinas sociológicas y semiótico-narrativas.

El corpus del estudio está conformado por 40 álbumes familiares, existiendo cinco muestras de cada década desde los años sesenta hasta la década actual. A partir de finales de los años noventa aparecen los álbumes digitales, que son los que se realizan a partir de imágenes digitales. Se configuran a partir de un programa informático y posteriormente se imprimen a través de páginas web especializadas o en tiendas de fotografía.

Los álbumes escogidos son los álbumes personales que se realizan de manera individual para cada hijo de la familia, ya que son los que tratan de explicar la historia de una vida. Los álbumes de acontecimientos concretos, como las bodas o los viajes, tienen una narrativa más corta y lo que interesa en el estudio es analizar la forma de hilvanar los recuerdos de un tiempo de vida largo.

Los álbumes analizados empiezan con el nacimiento del niño y terminan al cabo de unos años. Según la época, el final es más tardío o más cercano, pero lo normal es que duren hasta la primera adolescencia del niño, momento en que se dejan de hacer.

El análisis abarca un total de 4200 fotografías, que se han catalogado según criterios sociológicos, narrativos, compositivos, tecnológicos y descriptivos. Cada álbum tiene una media de 145 fotografías.

\section{Metodología}

La metodología utilizada para realizar el análisis es multidisciplinar, teniendo como base la sociología y la narrativa. Consideramos que la evolución plasmada en los álbumes digitales respecto a los analógicos es un reflejo de la evolución que ha sufrido la sociedad, tanto a nivel de cambios en los roles familiares como en los valores que se transmiten. A su vez, la narrativa es clave para entender el cambio en la manera de explicar la historia de nuestra vida a partir de las fotografías. El análisis es por tanto básicamente pragmático y además de las disciplinas descritas contiene una perspectiva tecnológica, semiótica y compositiva.

La pragmática, según Ch. Morris "es aquella parte de la semiótica que se ocupa de los orígenes, usos y efectos de los signos en el ámbito comportamental en que aparecen". (en Pericot, 198: 158) De esta manera, no se analizan las imágenes cómo enunciados independientes, sino como partes de un todo. No se puede considerar la imagen de forma aislada, ya que es parte de un fenómeno comunicativo global: el álbum de fotografía. Las circunstancias históricas y sociales del momento en que fueron captadas las instantáneas también son estudiadas. Es decir, se considera que las fotografías son un acto de comunicación de naturaleza pragmática. 
Para poder llevar a cabo este estudio se ha realizado una parrilla de análisis original. La parrilla ofrece seis bloques de información fundamentales: el álbum como objeto, los elementos descriptivos, la tecnología, la composición, los elementos de representación social y la narración.

\subsection{El primer bloque: El álbum como objeto}

En este primer bloque se cataloga el álbum según los criterios siguientes:
1. Número de fotografía
2. Familia a la que pertenece
3. Dibujo de la tapa
4. Material del álbum
5. Color
6. Marca
7. Tipo de páginas
8. Nombre del álbum
9. Temática del álbum

10. Índice

11. Número de fotografías

12. Clasificador de las fotografías

13. Edad del clasificador de las fotografías

14. Lugar en que se guarda el álbum

15. Frecuencia de observación de las fotografías

Se analiza el álbum como artefacto, teniendo en cuenta sus características físicas. Se observan así los cambios que han sufrido los álbumes a lo largo del tiempo, fruto de las modas y la tecnología.

Y se recogen también los datos pertenecientes a qué miembro de la familia es el encargado de clasificar las fotografías en los álbumes, dónde se guardan, si se contemplan a menudo... Para poder acceder a esta información, el análisis individual de los álbumes por parte del investigador se ha completado con un cuestionario que ha respondido cada familia, en el que se preguntaba todos aquellos datos imposibles de obtener a través de la simple observación.

\subsection{El segundo bloque: Los elementos descriptivos}

En este bloque los criterios son los siguientes:

1. Espacio (interior / exterior)

2. Espacio (público / privado)

3. Lugar

4. Ciudad

5. Año

6. Contexto temporal

7. Estación del año

8. Autor de la fotografía

9. Edad del autor

10. Edad principal representada

11. Sexo principal representado

12. Número de personas

13. Tipo de personas

14. Vínculo

15. Generaciones representadas

16. Presencia del protagonista
17. Presencia de la madre

18. Presencia del padre

19. Presencia de hermanos

20. Presencia de la familia no nuclear

21. Presencia de personas del ámbito no familiar

22. Instituciones

23. Pose

24. Clichés temáticos

25. Emoción representada

26. Expresión del protagonista

27. Actividad principal representada

28. Formalidad

29. Vestuario

30. Mirada

31. Manifestaciones amorosas 
A partir de estos marcadores se obtienen datos que permiten tener una descripción exhaustiva de los elementos discursivos presentes en la fotografía, ya sean los individuos, los espacios o los tiempos.

A través del estudio de la presencia de los distintos miembros familiares se establece una evolución de los cambios den los roles de la familia y la importancia de cada miembro.

Numerosas interpretaciones sociológicas pueden hacerse también a partir de la interpretación de los datos respeto a la formalidad, el vestuario, las instituciones y las actividades desarrolladas en las fotografías.

Cómo consideramos la actividad comunicativa de forma sincrética, no como una comunicación basada sólo en la palabra, la comunicación no-verbal es significativa y aporta información relevante.

\subsection{El tercer bloque: La tecnología}
1. Color o $\mathrm{B} / \mathrm{N}$
6. Elementos no fotográficos
2. Dispositivo
7. Texto
3. Exhibición
8. Retoque
4. Iluminación
9. Elementos auxiliares
5. Defecto

En esta parte se catalogan las fotografías según la tecnología con la que han sido tomadas y posteriormente guardadas. Un listado de los defectos más comunes también nos permite deducir cuáles son los elementos que se consideran más importantes de la fotografía, por encima de la técnica. Y la enumeración de todos aquellos elementos no fotográficos que se almacenan en algunos álbumes refleja el carácter autobiográfico y fetichista de estos objetos.

\subsection{El cuarto bloque: La composición}
1. Tipo de fotografía
2. Tipo de plano
3. Punto de vista
4. Objetivo
5. Formato
6. Margen
7. Orientación
8. Profundidad de campo
9. Posición del motivo
10. Velocidad de obturación
11. Clichés compositivos
12. Aire

Este cuarto bloque analiza las imágenes des del punto de vista compositivo. A pesar que la mayoría de autores de las fotografías domésticas se consideran simples aficionados sin preocupaciones estéticas, veremos como la composición amateur tiene también unas características propias que se repiten a través de las décadas. Cada fotógrafo toma una serie de decisiones cada vez que aprieta el disparador, fotografiar es un acto de interpretación (Gómez, 2010:54) ya que se prima una visión del mundo frente a otra. Y los álbumes de familia ofrecen imágenes muy similares en cuanto a la composición. 


\subsection{El quinto bloque: los elementos de representación social}
1. Relaciones de poder
6. Rito de paso
2. Elementos de clase
7. Rol
3. Tipo de celebración
8. Adecuación al rol
4. Momento de la celebración
9. Sobreactuación
5. Rito

En este bloque se estudian todos aquellos elementos de las imágenes que nos hablan de la situación en que fueron tomadas.

Las relaciones que se intuyen entre los miembros de las fotografías, los elementos que sirven para marcar la posición de clase y que refuerzan el rol de los personajes son analizados para poder establecer una pauta.

La fotografía es el testimonio de numerosos acontecimientos que sirven para definir el concepto de familia y en los que sus miembros ejecutan unos roles muy marcados. Los ritos y situaciones de carácter tradicional llenan las páginas de los álbumes y trataremos de buscar la respuesta a esta necesidad de preservar en imágenes estos momentos.

\subsection{El sexto bloque: La narración}

1. Serialidad

2. Número de la serie

3. Fotografías por página

4. Disposición de las fotografías

5. Modificación

6. Orden

7. Salto temporal entre fotografías
8. Relación entre las fotografías

9. Evidencia elemento omitido

10. Elemento nuevo relevante

11. Tipo de lectura

12. Trama

13. Roles narrativos

14. Estructura canónica

Este último bloque es uno de los más importantes ya que pretende comprender como los álbumes fotográficos exponen sus historias a modo de relatos. Las características narrativas y las tramas más presentes en los álbumes permitirán entrever una estructura que se repite y que tenemos interiorizada a la hora de elaborar un álbum fotográfico nuevo.

\section{Discusión}

Después de la recopilación de estos datos, la parrilla se ha dividido en tres partes diferenciadas, que corresponden a las cinco décadas estudiadas, que se agrupan en las tres épocas antes definidas: la modernidad, la tardomodernidad y la hipermodernidad.

Y con la ayuda de las tablas y gráficos dinámicos que genera el programa informático Excel, se han podido leer los datos de manera clara y visual, hecho que ha facilitado la tarea de recopilar la información para poder, posteriormente, elaborar las conclusiones.

Dos ejemplos de tablas dinámicas son los siguientes: 
1. Tabla dinámica simple de tipos de planos encontrados en todas las épocas. Fuente: Elaboración propia

\begin{tabular}{|l|c|}
\hline TIPO DE PLANO & Total \\
\hline plano general & 1830 \\
\hline plano medio & 848 \\
\hline primer plano & 344 \\
\hline plano americano & 79 \\
\hline plano detalle & 10 \\
\hline Total general & $\mathbf{3 1 3 9}$ \\
\hline
\end{tabular}

2. Tabla dinámica compuesta que muestra los escenarios mayoritarios según las distintas épocas. Fuente: Elaboración propia

\begin{tabular}{|l|c|c|c|c|}
\hline LUGAR & modernidad & tardomodernidad & hipermodernidad & Total general \\
\hline comedor & 221 & 253 & 352 & 826 \\
\hline hospital & 2 & 45 & 100 & 147 \\
\hline habitación & 13 & 51 & 58 & 122 \\
\hline escuela & 63 & 92 & 57 & 212 \\
\hline calle & 212 & 27 & 45 & 284 \\
\hline jardín & 89 & 121 & 19 & 229 \\
\hline Total general & $\mathbf{6 0 0}$ & $\mathbf{5 8 9}$ & $\mathbf{6 3 1}$ & $\mathbf{1 8 2 0}$ \\
\hline
\end{tabular}

Como ejemplos de gráficos dinámicos, que a partir de las tablas dinámicas se pueden obtener fácilmente, encontramos los siguientes:

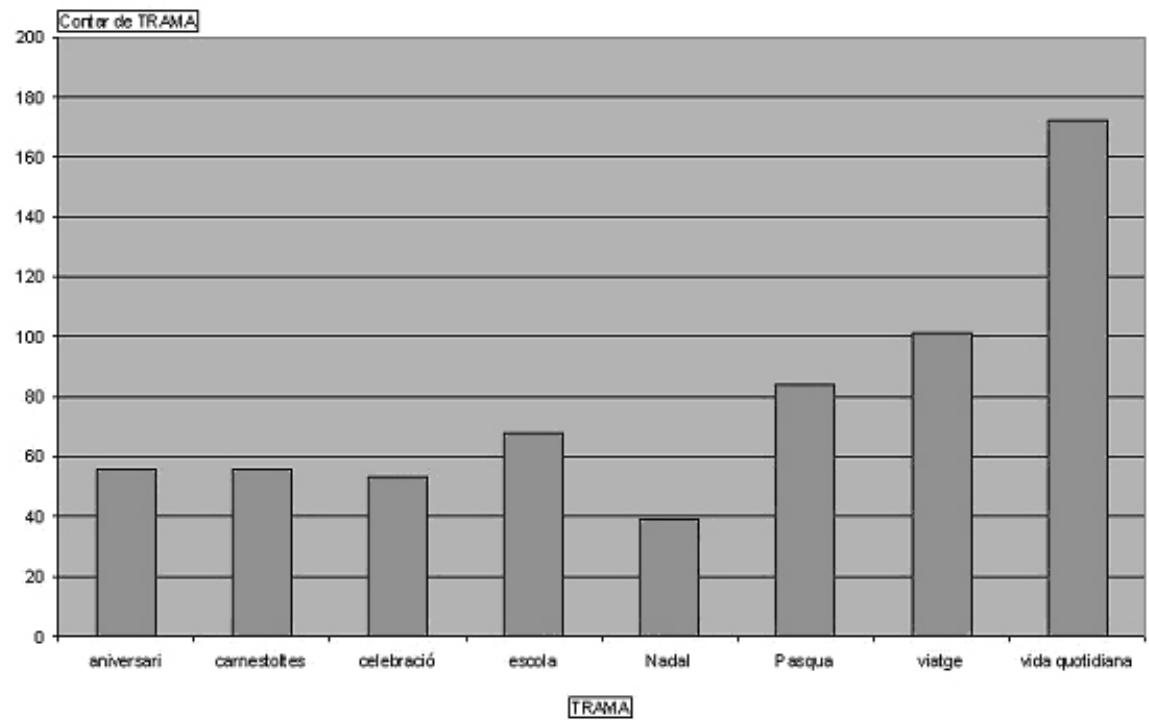

3. Gráfico dinámico que muestra las tramas más presentes en todas las épocas. Fuente:

Elaboración propia 


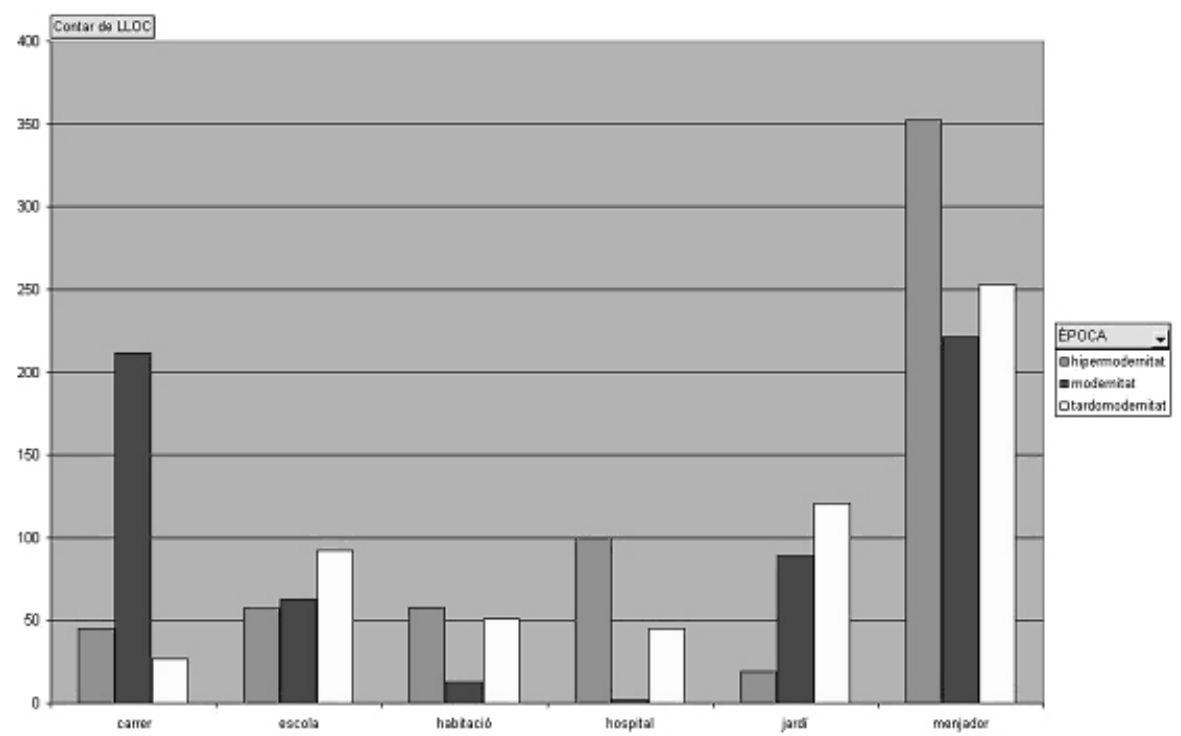

4. Gráfico dinámico que muestra las tramas más presentes según las tres épocas definidas

A partir de la recopilación de datos se extraen gran cantidad de conclusiones significativas.

Se observa cómo el paso de las décadas y los cambios de la sociedad se refleja en las fotografías a través de los cambios en los diferentes estadios fotográficos: en la toma de imágenes, en la selección del tema, en la ordenación y en la lectura posterior de las fotografías. La aparición de los álbumes digitales, a partir de finales de los 90, también ha supuesto un cambio importante en la narrativa fotográfica.

El estudio de la enunciación refleja los cambios que se han operado en el álbum como objeto. Ha dejado de ser un objeto único a poder ser reproducido más de una vez. El número de álbumes de temas diversos de los que dispone una familia también ha aumentado considerablemente.

Los espacios mostrados cada vez son más íntimos, y aparecen cada vez menos personajes. Los álbumes de la primera década del siglo XXI se centran en la figura del niño, que aparece en todas las fotografías, en planos muy cortos, hecho que convierte los álbumes en una operación que tiene mucho de narcisista. A nivel descriptivo, las fotografías de los álbumes digitales muestran espacios más interiores.

La técnica permite disparar muchas más fotografías de un mismo acontecimiento, dejando fuera de los álbumes las imágenes que presentaban defectos evidentes. Aún así, no se escoge ahora sólo la imagen que mejor ilustra el acontecimiento, sino que se relatan los sucesos a partir de gran cantidad de fotografías que reflejan el momento, pero también el antes y el después.

El estudio del enunciado nos muestra como los álbumes componen un relato socializado a partir de nuestra memoria. A pesar de la subjetividad que a priori podría habitar en los álbumes, vemos como la mayoría de sucesos recopilados son muy pa- 
recidos a lo largo de todas las muestras analizadas. La noción de identidad y de pertenecer a un grupo se hace evidente a partir de la reproducción de un modelo de vida similar en todos los álbumes.

Por lo que respecta a la representación social, se observa menos formalidad y menos poses a medida que pasan los años. Y una disminución de los rituales religiosos.

El análisis de las tramas más abundantes a lo largo de las distintas épocas nos muestra cómo no existen tramas originales en cada álbum, sino que se reproducen aproximadamente unas veinte, siendo algunas más importantes que otras según la década en que fueron organizados los álbumes. Los tramas que no aparecen a pesar de representar momentos importantes en nuestra vida también son estudiadas.

Respeto al análisis semiótico-narrativo, se observa como el niño es el sujeto de acción más habitual. Este no busca un objeto de valor concreto, sino que transita por una sucesión de programas narrativos que representan diversas estructuras canónicas, siendo la sanción positiva la más abundante.

Los modos de lectura y de ordenación ha supuesto uno de los cambios más notables de los álbumes digitales respeto a los analógicos. El mayor número de fotografías y el hecho de disponer de todas ellas antes de configurar el álbum, proponen nuevos modelos de distribución de las imágenes, dejando de ser el cronológico el único posible.

La lectura del álbum digital, por ejemplo, no es secuencial sino global. Las fotografías reproducen visualmente acontecimientos fotografiados de manera global, dónde cada imagen aporta una información a la idea general que se quiere transmitir. Los acontecimientos ya no son vistos de manera sucesiva y lineal.

Los álbumes digitales contienen una tapa dónde se puede colocar una imagen resumen. La similitud del álbum con un libro es así cada vez más notable. Si el álbum analógico era una carpeta ordenada, el álbum digital es un libro.

Por último, otro de los cambios importantes que conlleva la aparición del álbum digital es la imposibilidad de hacer modificaciones posteriores. El álbum ha dejado de ser un objeto vivo que se conformaba sobre la marcha. A la vez, los miembros de la familia ya no pueden descomponerlo ni modificar las imágenes que allí se guardan.

\section{Conclusiones}

La metodología utilizada permite obtener, como vemos, gran cantidad de datos. Hemos enumerado aquí sólo algunas de las conclusiones que pueden deducirse de la interpretación de datos de la parrilla anteriormente comentada. En cada una de las noventa categorías apuntadas puede hallarse información relevante para el estudio de los álbumes de fotografía como narración y como reflejo de la sociedad que los ha configurado.

Cabe incidir por último en una consideración derivada de este análisis. Y es que, a pesar de que en este estudio el álbum digital aparece como sustituto del álbum fotográfico analógico, no está claro que éste sea el sucesor definitivo del álbum. Creemos que las generaciones actuales todavía lo configuran como mimesis de lo que tradicionalmente han visto hacer a sus familias, pero que esta tendencia se irá perdiendo a medida que desaparezcan los referentes. Actualmente, la gente almacena sus 
fotografías de forma muy diversa, a la espera de la aparición de un formato definitivo para ordenarlas, sea o no de forma narrativa.

Si en los álbumes analógicos se reproducen temáticas socialmente arraigadas, siguiendo una especie de "modelo de vida" o guión cognitivo, y se dejan fuera (por desconocimiento o falta de modelos) otros usos narrativos posibles de la fotografía; las nuevas formas de organización que están apareciendo en los espacios virtuales, dónde la posibilidad de interacción y las opciones para configurar la visualización que tiene cada usuario cambian la organización y contemplación de las fotografías, establecerán nuevos guiones narrativos. De aquí pocos años se podrá comprobar si estas nuevas tecnologías aplicadas a la narración fotográfica familiar conllevan el establecimiento de un nuevo "modelo de vida", más acorde con las nuevas generaciones e inquietudes sociales actuales.

\section{Referencias bibliográficas}

BAUMAN, Zygmunt (2006): Vida líquida. Barcelona, Paidós.

BERGER, John (1997): Otra manera de contar. Murcia, Mestizo.

BOURDIEU, Pierre (2003): Un arte medio. Barcelona, Gustavo Gili.

CHALFEN, Richard (1987): Snapshot Versions of Life. Ohio. Bowling Green State University Popular Press: Bowling Green.

GARCÍA LÓPEZ, Javier (2011): "El efecto límite de la seducción publicitaria“. Revista de Comunicación Vivat Academia, ${ }^{\circ}$ 115, Junio 2011. Madrid.

GOFFMAN, Erving (2006): La presentación de la persona en la vida cotidiana. Buenos Aires, Amorrortu Editores

GÓMEZ, Hernando (2010): "El adjetivo visual. De la figura retórica al significado de la imagen fotográfica“. Revista de Comunicación SEECI, n 22, Julio 2010. Madrid.

GREIMAS, Julius (1976): Semántica estuctural. Madrid,Gredos.

LIPOVETSKY, Gilles (2004): Los tiempos hipermodernos. Anagrama, Colección argumentos.

PERICOT, Jordi (1987): Servirse de la imagen. Un análisis pragmático de la imagen. Barcelona, Ariel Comunicación.

SILVA, Armando (1999): Álbum de familia. La imagen de nosotros mismos. Bogotá, Colección vitral. Grupo editorial Norma.

RICOEUR, Paul (1987): Tiempo y narración. Vol. I. Madrid, Ediciones Cristiandad. RICOEUR, Paul (1987): Tiempo y narración. Vol. II. Madrid, Ediciones Cristiandad. VAN HOUSE, Nancy A., DAVIS, Marc; TAKHTEYEV, Yuri, AMES, Morgan; y FINN, Megan (2004): "The Social Uses of Personal Photography: Methods for Projecting Future Imaging Applications". Berkeley, University of California, Working Papers [http://people.ischool.berkeley.edu/ vanhouse/pubs.html] 


\section{Mariona VISA BARBOSA}

marionavisa@filcat.udl.cat

Doctora en Comunicación Social por la Universitat de Lleida (2012).

Profesora investigadora del Departamento de Filología catalana y Comunicación Universitat de Lleida 